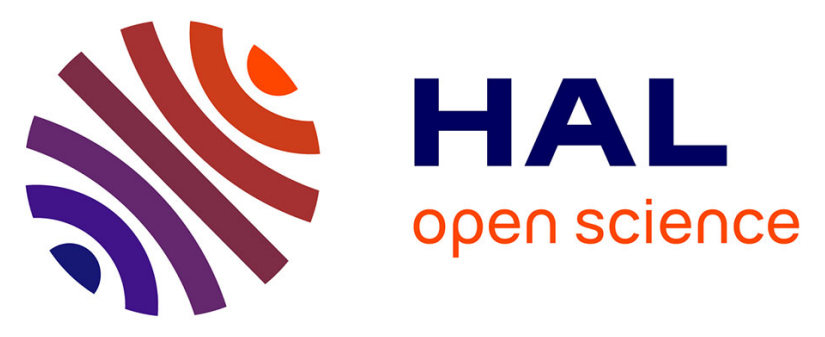

\title{
A Demo of the PEACH IoT-based Frost Event Prediction System for Precision Agriculture
}

Keoma Brun-Laguna, Ana Laura Diedrichs, Javier Emilio Chaar, Diego Dujovne, Juan Carlos Taffernaberry, Gustavo Mercado, Thomas Watteyne

\section{- To cite this version:}

Keoma Brun-Laguna, Ana Laura Diedrichs, Javier Emilio Chaar, Diego Dujovne, Juan Carlos Taffernaberry, et al.. A Demo of the PEACH IoT-based Frost Event Prediction System for Precision Agriculture. SECON 2016 - 13th Annual IEEE International Conference on Sensing, Communication and Networking, Jun 2016, London, United Kingdom. 2016, 10.1109/SAHCN.2016.7732963 . hal01311527

\section{HAL Id: hal-01311527 \\ https://hal.inria.fr/hal-01311527}

Submitted on 20 Dec 2016

HAL is a multi-disciplinary open access archive for the deposit and dissemination of scientific research documents, whether they are published or not. The documents may come from teaching and research institutions in France or abroad, or from public or private research centers.
L'archive ouverte pluridisciplinaire HAL, est destinée au dépôt et à la diffusion de documents scientifiques de niveau recherche, publiés ou non, émanant des établissements d'enseignement et de recherche français ou étrangers, des laboratoires publics ou privés. 


\title{
A Demo of the PEACH IoT-based Frost Event Prediction System for Precision Agriculture
}

\author{
Keoma Brun-Laguna*, Ana Laura Diedrichs ${ }^{\dagger} \uparrow$, Javier Emilio Chaar ${ }^{\ddagger}$, Diego Dujovne ${ }^{\S}$, \\ Juan Carlos Taffernaberry ${ }^{\dagger}$, Gustavo Mercado ${ }^{\dagger}$, Thomas Watteyne* \\ * Inria-Paris, EVA Team, France \\ $\dagger$ Universidad Tecnológica Nacional (UTN), Mendoza, Argentina \\ $\ddagger$ Instituto Nacional de Tecnología Agropecuaria (INTA), Junín, Mendoza, Argentina \\ $\S$ Universidad Diego Portales (UDP), Santiago, Chile \\ I CONICET, Mendoza, Argentina
}

\begin{abstract}
In 2013, 85\% of the peach production in the Mendoza region (Argentina) was lost because of frost. In a couple of hours, farmers can lose everything. Handling a frost event is possible, but it is hard to predict when it is going to happen. The goal of the PEACH project is to predict frost events by analyzing measurements from sensors deployed around an orchard. This demo provides an overview of the complete solution we designed and deployed: the low-power wireless network and the back-end system. The low-power wireless network is composed entirely of commercial off-the-shelf devices. We develop a methodology for deploying the network and present the open-source tools to assist with the deployment, and to monitor the network. The deployed low-power wireless mesh network, built around SmartMesh IP, is $100 \%$ reliable, with end-to-end latency below $2 \mathrm{~s}$, and over 3 years of battery lifetime.
\end{abstract}

Index Terms-Smart Agriculture, Precision Agriculture, IoT, SmartMesh IP.

\section{RElationship to PREvious Work}

This demo presents the PEACH project and the associated deployment running in Argentina. The PEACH project has been previously published [1]. Some text and figures in this extended demo abstract are borrowed from that publication.

\section{OVERVIEW}

In 2013, 85\% of the peach production in the Mendoza region (Argentina) was lost because of frost. Because less fruit was produced in the region, 600,000 less work days were needed to process the harvest between November 2013 and March 2014 , a reduction in work force of 10,600 people. Across the Mendoza region, frost caused a loss of revenue of 950 million Argentine pesos, roughly 100 million USD (at that time) in the peach business alone. A frost event happens when the temperature is so low that crops cannot recover their tissue or internal structure from the effects of water freezing inside or outside the plant.

Agronomists need precise and representative measurements to understand the impact of frost events on the plants. Today, virtually all industrial peach orchards are equipped with a meteorological station that monitors temperature and humidity. As the meteorological station only measures the environment in one location, this solution lacks spacial representation. Frost countermeasures exist, such as placing heaters across

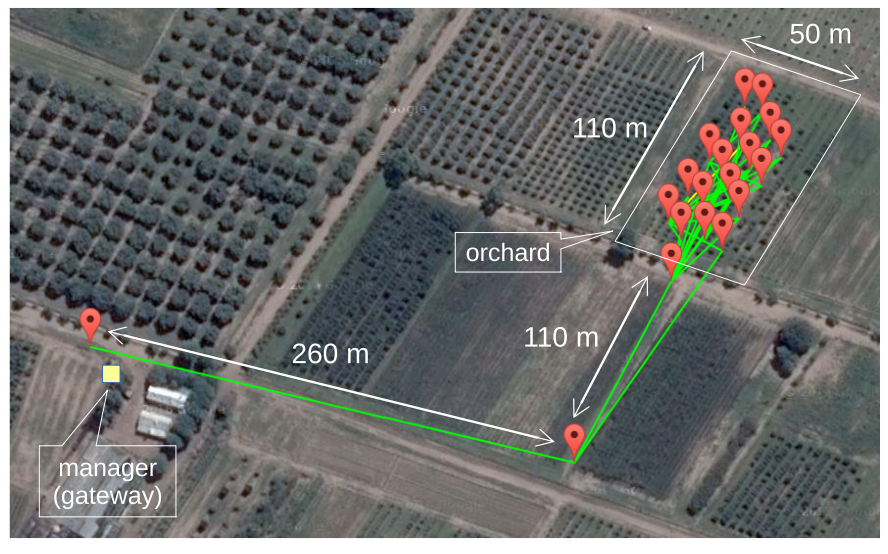

Fig. 1. The nodes and wireless links in the PEACH deployment.

the orchard or mixing air from above and inside the orchard, but those solutions are expensive. Temperature can vary $5 \mathrm{C}$ at different places in the same orchard; only a few degrees difference can mean flower buds freeze. It is therefore crucial to have spatially-distributed sensor measurements.

There is a need for a dense monitoring system to gather data that really represents the orchard environment. Because farmers use heavy machinery, using wires is not an option. We choose to use a low-power wireless mesh network to interconnect sensors densely deployed in the orchard. The security and reliability of those wireless networks must be equivalent to that of its wired counterpart. Our target battery lifetime for the devices is "at least a year", the natural grow cycle of peaches. Our goal is to retrieve representative measurements that agronomists can analyze to understand and predict frost events in peach orchards. What we build is a system with a large number of sensing points (air temperature, air relative humidity, soil moisture, soil temperature), at different elevations/depths throughout the orchard.

\section{The PEACH DEPLOYMENT}

The PEACH network consists of 21 low-power wireless motes deployed in a peach orchard in Junín, a city close to Mendoza, in the West of Argentina. We use SmartMesh IP motes produced by Linear Technology as it offers best-in-class 


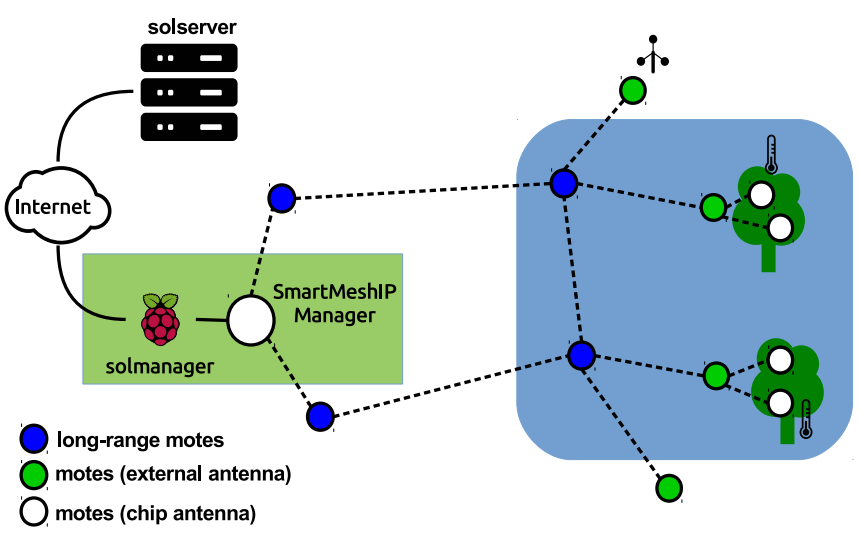

Fig. 2. Architecture of the PEACH network.

$>99.999 \%$ end-to-end reliability and can run over a decade on a pair of AA batteries [2]. A temperature sensor is built into the motes, publishing a measurement every $30 \mathrm{~s}$. The motes themselves produce network statistics (called "Health Reports") such as the number of neighbors or the amount of charge consumed by the mote, every $15 \mathrm{~min}$. All the information produced by the network (sensor measurements and network statistics) is sent to the network gateway, a SmartMesh IP Manager.

We call "back-end" the system that connects to the SmartMesh IP Manager, retrieves all the information produced by the mesh network, and sends those to a remote database. The back-end is composed of two software components, the solmanager and the solserver. A Raspberry Pi singleboard computer is connected to the SmartMesh IP Manager over USB, and runs the solmanager application that serves as an interface between the mesh network and the Internet. The solmanager transmits all the information the SmartMesh IP Manager receives to a remote server located in the Inria-Paris research center. This server runs the solserver application. The solserver application stores the data into a database and allows users to visualize the sensors measurements seconds after they were acquired in the orchard in Argentina. We use a Grafana dashboard (Fig. 3) to show the measurements, and a map to show the network (Fig. 1), in real-time ${ }^{1}$.

The solserver supports multiple solmanager instances. This means that we can easily deploy a new mesh network and, by running a new solmanager application, forward all the mesh data to the existing solserver. Each mesh network is called a "site"; we show in this demo how to add a new site.

All the deployment details can be found on the project website ${ }^{2}$.

\footnotetext{
${ }^{1}$ https://sol.paris.inria.fr/

2 https://www.savethepeaches.com/
}

\section{SOL: THE SENSOR OBJECT LIBRARY}

The PEACH deployment uses the "Sensor Object Library" (SOL), a library we developed to use a generic representation for the data produced by the mesh network. The format of the data generated by the SmartMesh IP network depends on the application that runs on the motes. We created the SOL library to wrap the information generated by the SmartMesh IP as SOL objects, composed of the following fields: the identifier of the device generating the information, the timestamp of when the information was generated, the type of information and the value of the information. A SOL object can be seen as a generalization of the Type-Length-Value (TLV) format. The SOL registry contains the list of SOL types currently used, and their associated format. The SOL registry is publicly maintained and can be easily augmented with new types of sensor data ${ }^{3}$.

Both the solmanager and solserver applications use the SOL library. As the data transits from the mesh network to its final destination (i.e. the database), it is subject to multiple format changes. The solmanager turns the SmartMesh IP data into easy-to-manipulate SOL objects in JSON format, then turns those SOL objects in a lightweight binary format to be sent to the solserver. The solserver turns the objects back into JSON format and parse them before storing them into the database.

\section{Performance Results}

We know how the network behaves from the Health Reports retrieved at the SmartMesh IP Manager. After 3 weeks of deployment the mesh network has a $100 \%$ end-to-end reliability, $97 \%$ stability, $800 \mathrm{~ms}$ latency.

The network reliability indicates the portion of the packets generated by the motes that reach the SmartMesh IP manager. The motes have generated 483,114 packets, all successfully received by the SmartMesh IP manager (possibly after multiple hops), yielding $100 \%$ reliability.

The network stability represents the average Packet Delivery Ratio (PDR) over all wireless links. The motes have sent 3,009,962 data-link frames, 93,985 unsuccessfully (i.e. no link-layer acknowledgment was received), yielding a network stability of $97 \%$. This number is very high, indicating that the nodes are deployed close enough in an environment with little external interference and multi-path fading.

The network latency represents how long a packet is traveling in the multi-hop wireless mesh network. In the PEACH deployment, it takes on average $800 \mathrm{~ms}$ for a sensor measurement to travel from the mote that generated it to the SmartMesh IP manager, over the multi-hop low-power wireless mesh network. The latency depends on the number of hops. Currently, the furthest mote is 5 hops away from the manager; it has a latency of $1540 \mathrm{~ms}$. This latency is small compared to the variation speed of the signal we are observing (temperature).

\footnotetext{
${ }^{3}$ https://github.com/realms-team/sol/blob/master/registry.md
} 


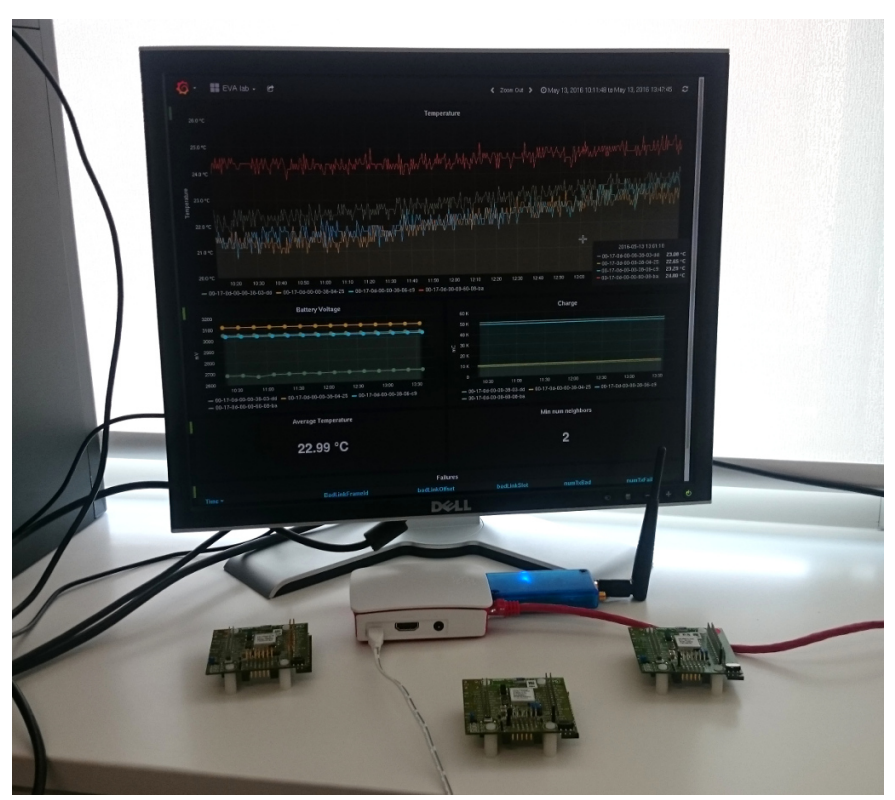

Fig. 3. The setup of the PEACH demonstration, including the motes, the manager and the web interface of the back-end system.

\section{RELATED DEPLOYMENTS}

An equivalent network is deployed for monitoring the plants in the UC Berkeley Botanical Garden ${ }^{4}$. This botanical garden has over 13,000 different kinds of plants from around the world cultivated over an area of 34 acres. The different needs of each plant makes the irrigation a complex task; the mesh network is deployed to help the local botanist team get in-situ measurements.

The ARHO project is adopting the back-end system presented in this extended abstract. In the ARHO project, 945 sensors are deployed in the California Sierra Nevada to monitor the snow-pack [3]. The sensors are organized in 15 low-power wireless 15 networks, each one covering 1-2 $\mathrm{km}^{2}$.

\section{THE PEACH DEMO}

During the demo, we replicate the PEACH network presented in Section III. We deploy SmartMesh IP motes across the conference venue. They form a low-power wireless mesh network around the SmartMesh IP Manager, which is connected to a computer. Sensor measurements and network statistics are forward by this computer to the back-end system running at Inria-Paris. Visitors can see the data live at https://sol.paris.inria.fr/. During the demo, we have the system reset; visitors witness how the reliable wireless mesh network is formed. A picture of the different elements shown during the demo is shown in Fig. 3.

This demo presents the technology as a turn-key solution. We are interested in partnering with end users and integrators to replicate the PEACH network to other deployments and applications.

\footnotetext{
4 "Student-installed Sensors Help Monitor Botanical Garden", http://news. berkeley.edu/, 20 October 2015.
}

\section{LESSONS LEARNT, ONGOING WORK AND ROADMAP}

\section{A. Lessons Learnt}

Although frost events may appear harmless, they yield enormous losses in fruit production, for example peaches. As seen throughout this project, IoT technology is ready for this type of precision agriculture applications. The main outcome of this project is a perfectly working end-to-end lowpower wireless distributed sensor system, built exclusively from commercial off-the-shelf components. Deploying such a network took a couple of hours, putting the whole hardware and software together a couple of days.

In a decade, wireless sensor applications went from boards programmed from scratch with a combination of the most promising research papers, to using off-the-shelf products implementing standards-based fully working and mature technology. Wireless Sensor Networks/Internet of Things technology successfully transitioned from the academic to the commercial world.

\section{B. Ongoing Work and Roadmap}

A lot still needs to be done. The first step is to add additional sensors to the motes, including relative air humidity, soil moisture, soil temperature and soil conductivity. We then plan to apply machine learning techniques, in particular ensemble regression-tree, on the large-scale network statistics and measurements dataset. On the application side, we want to be able to identify frost events patterns and thus, be able to predict them. On the networking side, we are particularly interested in studying the maximal capacities of the IEEE802.15.4e "Time Synchronized Channel Hopping" (TSCH) standard that is used in those deployments.

The combination of technologies is perfectly suited for micro-climatic modeling in precision agriculture, and we believe it is also perfectly suited for other fields. We are looking to apply this proven technology in other precision agriculture applications and to extend this work to other domains, including infrastructure monitoring and building automation.

\section{ACKNOWLEDGMENTS}

The authors thank the Dust Networks product group at Linear Technology and Metronome Systems for their technical support. This publication was made possible by the support of the STIC-AmSud program, under grant 16STIC08-PEACH and by Inria, through the REALMS associate team.

\section{REFERENCES}

[1] T. Watteyne, A. L. Diedrichs, K. Brun-Laguna, J. E. Chaar, D. Dujovne, J. C. Taffernaberry, and G. Mercado, "PEACH: Predicting Frost Events in Peach Orchards Using IoT Technology," EAI Endorsed Transactions on the Internet of Things, vol. to appear, no. to appear, p. to appear, 2016.

[2] T. Watteyne, J. Weiss, L. Doherty, and J. Simon, "Industrial IEEE802.15.4e Networks: Performance and Trade-offs," in International Conference on Communications (ICC). London, UK: IEEE, 8-12 June 2015.

[3] Z. Zhang, S. Glaser, T. Watteyne, and S. Malek, "American River Hydrological Observatory: Monitoring the Sierra Nevada Snowpack," IEEE Internet of Things Journal, vol. XX, no. X, pp. XX-xx, 2016, [under review]. 